\title{
The relationship between internationalisation, creativity and transformation: A case study of higher education in Hungary
}

\begin{tabular}{|c|c|}
\hline \multicolumn{2}{|c|}{$\begin{array}{l}\text { Authors: } \\
\text { Melanie K. Smith } \\
\text { Vilmos Vass }\end{array}$} \\
\hline \multicolumn{2}{|c|}{$\begin{array}{l}\text { Affiliations: } \\
{ }^{1} \text { School of Tourism, Leisure } \\
\text { and Hospitality, Budapest } \\
\text { Metropolitan University, } \\
\text { Hungary }\end{array}$} \\
\hline \multicolumn{2}{|c|}{$\begin{array}{l}{ }^{2} \text { Institute of Social Sciences } \\
\text { and International Relations, } \\
\text { Budapest Metropolitan } \\
\text { University, Hungary }\end{array}$} \\
\hline \multicolumn{2}{|c|}{$\begin{array}{l}\text { Corresponding author: } \\
\text { Vilmos Vass, } \\
\text { vvass@metropolitan.hu }\end{array}$} \\
\hline $\begin{array}{l}\text { Dates: } \\
\text { Received: } 09 \text { I } \\
\text { Accepted: } 07 \\
\text { Published: } 18\end{array}$ & $\begin{array}{l}\text { May } 2017 \\
\text { Aug. } 2017 \\
\text { Sept. } 2017\end{array}$ \\
\hline \multicolumn{2}{|c|}{$\begin{array}{l}\text { How to cite this article: } \\
\text { Smith, M.K. \& Vass, V., 2017, } \\
\text { 'The relationship between } \\
\text { internationalisation, } \\
\text { creativity and transformation: } \\
\text { A case study of higher } \\
\text { education in Hungary', } \\
\text { Transformation in Higher } \\
\text { Education 2(0), a22. https:// } \\
\text { doi.org/10.4102/the.v2i0.22 }\end{array}$} \\
\hline \multicolumn{2}{|c|}{$\begin{array}{l}\text { Copyright: } \\
\text { (c) 2017. The Authors. } \\
\text { Licensee: AOSIS. This work } \\
\text { is licensed under the } \\
\text { Creative Commons } \\
\text { Attribution License. }\end{array}$} \\
\hline \multicolumn{2}{|l|}{ Read online: } \\
\hline 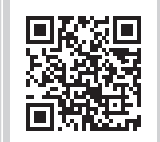 & $\begin{array}{l}\text { Scan this QR } \\
\text { code with your } \\
\text { smart phone or } \\
\text { mobile device } \\
\text { to read online. }\end{array}$ \\
\hline
\end{tabular}

The main objective of this article is to explore the relationship between internationalisation, creativity and transformation in the context of higher education. It is argued in academic theory that the process of internationalisation in higher education has two pillars: transformational learning and creative development, and that creativity is an integral part of transformational learning. To explore this relationship further, the authors draw on primary research undertaken in the context of a higher education institution in Budapest, Hungary. A Delphi study with senior academic staff and a focus group with Hungarian and international students were included in the research. Questions were asked which aimed to determine whether creativity is indeed an integral part of transformational learning, and whether creativity and transformation are the most important elements of internationalisation. Staff and students recognise the creative and transformative potential of internationalisation, but they also identified several challenges. These include encouraging students to go beyond instrumental approaches to learning, providing staff with the relevant training and support, changing the culture of institutions and overcoming the lack of flexibility in existing national education structures. Overall, the research findings reinforced theoretical perspectives, which propose creative thinking, cooperative and communicative learning, project-based and problem-solving activities as some of the main tools in the process of transformational learning and prerequisites for internationalisation.

\section{Introduction}

Universities are knowledge-producing entities and have social, cultural, ideological, political and economic responsibilities to society.

(Maringe \& Foskett 2010:1)

This article focuses on the relationship between internationalisation, creativity and transformation in the context of higher education. Du Preez, Simmonds and Verhoef (2016:2) argue that internationalisation is 'one of the directions that transformation of higher education must take'. It has been argued in academic theory that the process of internationalisation in higher education has two main pillars: transformational learning and creative development, and that creativity is an integral part of transformational learning. To verify whether transformational learning and creative development are indeed essential elements in the process of internationalisation, the authors draw on primary research undertaken in the context of a higher education institution in Budapest, Hungary. A Delphi study with senior academic staff and a focus group with Hungarian and international students were included in the research. Questions were asked which aimed to determine whether creativity is indeed an integral part of transformational learning, and whether creativity and transformation are the most important elements of internationalisation.

\section{An overview of transformational education}

Transformation has been defined in different ways according to context and discipline or field. Within a business context, Pine (2015) and Pine and Gilmore (2014) suggest that one of five valuecreating opportunities that are likely to drive further progress in the dynamic experience economy are 'transformative experiences'. This means that customers are looking for even longer-lasting benefit or value and may wish to be changed by their experiences, realising dreams or achieving aspirations. Such a notion might fit very well into an educational context, especially as students are increasingly perceiving themselves as 'customers' who are buying into an educational experience. Mermiri (2009) describes how the transformation economy is characterised by 
'meaning' and 'interaction'. Products and services are chosen based on how they will transform people's lives or ways of thinking. In the transformation economy, goods and services are co-created or co-produced through the interaction of consumers and producers. The consumer helps to shape the product or service which can transform the individual. Again, a similar or parallel process might take place in educational contexts where education is becoming (1) transformational and (2) (co)creative.

Specifically within an educational context, Du Preez et al. (2016) suggest that transformation is an inherently complex, fluid, open-ended construct, which can refer to changes in institutional structures and culture, as well as to specific elements such as curriculum and academic and student experiences. Mezirow (1978) was one of the first theorists to apply the concept of transformation to learning. He states that development of a new worldview is at the heart of transformational learning. Anderson and Anderson (2001) concurs with this idea that transformational change means a broadening of people's worldview. Tolliver and Tisdell (2006) suggest that a more expansive understanding of the world can be grounded in our own beings, and transformational learning focuses on a change or shift in one's way of being in the world, understandings of oneself and relationships with others (Morell \& O'Connor 2002). Several other authors have supported this view that transformational learning fosters a broader conception of the self (Cranton 1994; King 1996; Quinn 1996). Clark (1991) identifies three major outcomes of transformation: psychological (a person changes an understanding of the self), convictional (a person revises their own belief systems) and behavioural (a person makes changes to their lifestyle). Transformational learning clearly involves an existential component (Holland-Wade 1998). Sohn et al. (2016) state that:

\footnotetext{
we contend that teaching for transformation is more than good teaching because it focuses on helping students to transcend mastery of course content and find deep, personal meaning in their learning experiences and lives through realization. (p. 183)
}

Another major part of transformation is connecting and communicating with others, that is, socialisation (Mezirow 2000). Social relationships help individuals to develop openness and self-understanding and to build confidence and self-esteem (Holland-Wade 1998). Mezirow (1991) also emphasised the importance of critical reflection, which can transform beliefs, attitudes, opinions and reactions. Merriam (2004) states the importance of cognitive development in transformational learning, but Pierce (1986:273) suggests that transformational learning places as much value on emotional and experiential components of learning as on cognitive and intellectual elements. Clark and Wilson (1991) and Dirkx (2008) also mention irrational and emotional aspects of learning. Sohn et al. (2016:186) describe how transformational learning 'explores a whole-learner perspective rather than viewing learning as knowledge and skill acquisition focused solely on cognitive reflection and perspective building'.
Mezirow (1994) states that most (adult) education is about instrumental learning that has clearly defined learning objectives, tasks and outcomes, as well as competencies and skills. Learners tend to follow teachers' ways of thinking. Instead, however, 'communicative learning' can help address change in oneself and the way one learns. Dirkx (2008) states that transformational learning challenges common assumptions, notions and meanings of what learning is all about. Stone and Duffy (2015) suggest that:

The opportunity to engage in this kind of learning process is vital for students who hope to thrive in a global marketplace and diverse industry where core beliefs and worldviews, which act as either barriers or bridges to successful problem solving and a flourishing career, will constantly be challenged. (p. 107)

\section{The role of creativity in transformational education}

One of the most relevant and pragmatic answers to the challenging question of globalisation in higher education is internationalisation (Blessinger 2015). There are several papers, publications, strategies and theoretical models on this topic (Cheng, Wang \& Liu 2014; De Witt et al. 2017; Maringe \& Foskett 2010). From a practical point of view, it is proposed that these approaches can be integrated into a new conceptual framework. This framework has two pillars: transformational learning and creative development in higher education.

It is clear from the previous section that transformational learning and education should focus on existential, experiential, social and communicative dimensions. It should challenge learners' basic assumptions and even their worldview. It should create meaning and even changes lives. However, what then is the link to creativity? It was already stated in business literature that the transformation economy requires some degree of 'co-creation' between suppliers and customers (Pine 2015; Pine \& Gilmore 2014). Mermiri (2009:21) even suggests that creativity is a key constituent in the transformation economy.

Creativity has played an important role in research, education, economy and society since 1950, reflected in numerous publications containing quantitative and qualitative research data and analysis (Csikszentmihalyi 1996; Sternberg 1999). It should be noted that there is a considerable body of literature on creativity and education, which was too extensive to be included there. However, many of the studies focus on primary or secondary education rather than higher education. Several systematic reviews or metaanalyses summarise this literature (e.g. Davies et al. 2013; Mullet et al. 2016). Jackson et al. (2006) suggest that the importance of creativity had not yet been properly recognised within higher education, but recent publications focus on a higher education perspective. The authors of this article concur with Watts and Blessingers's (2017) thoughts on creative learning in the context of higher education, namely that it is process and outcome oriented, it is domain and field specific and it is connected to the sociocultural environment. 
These ideas follow on from those of Csikszentmihalyi and Sawyer (1995). Csikszentmihalyi (1996:23) states that 'creativity does not happen inside people's head, but in the interaction between a person's thoughts and a social cultural context'. Sternberg (1999) subsequently defines a 'socialpersonality approach' to creativity. Beghetto and Kaufman (2013) outline some fundamentals of creativity, namely: (1) creativity takes more than originality, (2) there are different levels of creativity, (3) context matters, (4) creativity comes at a cost and (5) there is a time and a place for creativity. In addition, creativity has some general characteristics: (1) transversal competence through all subject areas concerned and (2) transdisciplinarity, which orients curriculum planning and creativity development.

One of the challenges is defining creativity in the context of education (Bereczki 2016). Bronson and Merryman (2010) suggest that although creativity has always been prized in the American society, it has never really been understood. Jones (2009) asks how creativity can be adequately and fairly assessed if each discipline values and frames it differently. It is important to define what creativity can mean in the context of education, but also how it is interpreted in different languages and contexts. Philip (2015) suggests that creativity can be hidden in the higher education curriculum, often under the guise of problem-solving, critical thinking or communication. Although creative education seems to have become a priority within many countries, the approach may differ considerably. Radclyffe-Thomas (2015:159) notes that this can have implications for internationalisation in higher education with the recruitment of students from different countries and cultures. He states that 'the notion of creativity as understood and interpreted in different cultural settings, and in cross-cultural settings is worthy of further exploration'. Research has shown that the stimulation and development of creative abilities and intercultural skills help prepare children for life in a globalised and multicultural world (Dziedziewicz, Gajda \& Karwowski 2014).

Urban (2014) emphasises the importance of divergent thinking (generating unique ideas) for creativity, and Bronson and Merryman (2010) add convergent thinking, which combines these ideas into the best results. Flint (2014) suggests that creative approaches to education should include thinking interdependently, gathering data through all the senses, adopting a multidisciplinary perspective, and mixing movement, drama and music with academic content. This raises the question of how far an arts-based or arts-led education is necessary to engender creativity. Mermiri (2009:9) suggests that 'culture and the arts can [also] be deeply moving and transformational, often shaping individual and collective identity by appealing both to the aesthetic and the emotional'. Munday (2016), on the other hand, questions whether the arts and artists can truly facilitate and foster the emergence of innovative executives and entrepreneurs. He notes that artists actually rarely label themselves as 'creative'. It is arguably possible for creativity to reside in other subject areas and approaches. For example,
Bronson and Merryman (2010) quote researchers who say that creativity should be taken out of the art room and put into homeroom.

As a summary, therefore, it seems that understandings of creativity vary according to culture and context, creative abilities are important in the context of internationalisation and multiculturalism and although the arts can be important for creativity, it is not only through the arts that creativity may be fostered. These ideas will form part of the questions posed to both academic staff and students later in the case study research.

The case study provides a context for the main research questions, which aimed to determine whether creativity and transformation are the most important elements of internationalisation, and whether creativity is an integral part of transformational learning. Compared to the plethora of research on Western European and North American education systems and the growing number of case studies from Asia, there have been relatively few from Central and Eastern Europe (Watts \& Blessinger 2017). The authors therefore aimed to bridge this gap with a case study of Hungary.

\section{A brief overview of the Hungarian educational context: Transformation, diversity and creativity}

Zsolnai and Lesznyák (2015) explore the link between political changes, education and values in Hungary from 1990 to 2012. After the transition (the post-1989 period following the fall of Communism), they describe a 'crisis of values' followed by an increase in decentralisation, democracy and autonomy. They discuss how Szabó, Bauer and Laki (2001) revealed that the most important trait in young people's value profile was an instrumental approach towards education (i.e. a belief that qualifications and professions are important but that institutions and teachers cannot shape lives). They also quote Bauer and Szabó (2009) who interestingly state that one of the most important values for young people after the change of regime was 'creativity'. Bereczki's (2016) analysis of creativity in the Hungarian national curriculum (HNCC) in 2012 suggests that creativity is not clearly defined, there is greater emphasis on creativity at primary level, and that there was a significant imbalance across subject groups. She concludes that:

though explicit references to several elements of the creative learning environment appear across the HNCC, the analysis highlighted the lack of attention to important conditions of creative learning suggested by the literature. (Bereczki 2016:350)

However, Messing (2008) comments on how the most successful pedagogical methods in bridging the educational gap between Roma and non-Roma in Hungary (a common and controversial theme in educational literature because Roma or Gypsy children are often less educated or 
are educated in segregated schools) was through 'transformational' or 'creative' activities such as cooperative and project-based learning, drama and cultural trips.

Post 2012, Hungarian education has become more centralised again, and Zsolnai and Lesznyák (2015) pose the question whether post-communist humanistic and democratic values will remain. In the South African context, Du Preez et al. (2016) suggest that the transformation of higher education should help create greater access to disadvantaged groups, internationalisation should be a key factor of transformation and that transformation is not simply a goal in itself, but a way of improving and creating a more equitable society. Although the South African context is very different from the Hungarian one, it could be argued that these values have a global resonance everywhere, especially in a country whose democratic status is currently being questioned (Szikra 2014).

\section{A case study of Budapest Metropolitan University}

Budapest Metropolitan University is the largest private university in Hungary with a student community of almost 8000. It offers a wide selection of bachelor and master degree programmes in the fields of communication, business, tourism and arts. Although the internationalisation of the university is relatively recent (the past four years), international students already come from 75 countries. Budapest Metropolitan University cites creative education as a 'core value' which is embodied in the teaching methods, the approach to teaching and learning and in students' attitude. The fostering of creative thinking is described as a key to their future success (Budapest Metropolitan University 2017).

\section{Research methods and design}

The main research questions aimed to explore whether creativity and transformation are the most important pillars of internationalisation, and whether creativity is integral to transformational learning. The research methods were designed to consider these relationships from the perspectives of both academic staff members and students.

A Delphi study was undertaken with senior members of staff from Budapest Metropolitan University. A Delphi study can be described as 'a research approach to gain consensus using a series of questionnaires and the provision of feedback to participants who have expertise in key areas' (Habibi, Sarafrazi \& Izadyar 2014:12). Researchers send a set of questions or a questionnaire to a number of carefully selected expert respondents who are asked to complete the questions and send back their responses to the researchers. The researchers analyse the responses and send them back to the respondents for further comments and reflections, often with structured questions attached which aim to encourage agreement or consensus on key themes. This can happen two times or more until consensus is reached. Although there are debates about the optimum number of participants, Okoli and Pawlowski (2004) suggest that most Delphi studies have only 10-18 participants. This Delphi Panel had 10 members who were considered to be educational experts and consisted of heads of departments or programmes (e.g. BAs, MAs, Languages, International Student support), as well as Rectors, Vice Rectors and Deans. A minimum of two rounds of questions is suggested (Gordon 1994), and this Delphi study accorded with this criterion. Open questions were distributed in the first-round questionnaire as advocated by Brady (2015), and questions inviting agreement or consensus were designed in the second round, as reaching consensus on issues is the main aim of a Delphi study (Hsu \& Sandford 2007). The researchers designed and distributed the questions electronically over a period of several weeks with a one-month gap in between rounds. The open questions asked respondents to reflect on the nature of and relationships between transformational education, creativity and internationalisation. In the second round, respondents were asked to reflect on the summary of findings and to agree on key definitions and relationships. The responses were all given in written form.

A focus group was also undertaken with eight students from Metropolitan University. They were carefully selected from courses that had been taught by the researchers which had contained some elements of creative content and delivery. The researchers were also the moderators, so this selection could technically have biased the results. However, it was important that the focus group participants could understand these sophisticated concepts and that they were articulate with good enough English language skills to participate. After this selection, the open questions focused on the students' opinions about their educational experiences and how creative, international and transformational they were. There were four Hungarian students and four international students, five female and three male, from both BA and MA programmes. In accordance with research methods theory, the focus group size was optimum. MacDonald and Headlam (2011) suggest that 6-12 participants is normal and Krueger (2002) states that 6-8 is ideal. An hour-long focus group is typical and a range of 45 to $90 \mathrm{~min}$ is acceptable (Eliot \& Associates 2012). The focus group took $80 \mathrm{~min}$. It took place in a familiar location (a classroom in the university). Chairs were arranged in a circle, drinks and snacks were provided and the session was recorded and notes were taken as recommended by several authors (e.g. Krueger 2002; MacDonald and Headlam 2011). All students contributed to the discussion, although there were one or two 'dominators' and one or two 'shy participants' (cf. Eliot \& Associates 2012) as could be expected. The responses were all given in oral form, recorded and then transcribed by the researchers.

\section{Results}

The Delphi study and the focus group yielded some interesting results which are presented in the following sections. Both groups were asked to comment on the three main themes of internationalisation, creativity and transformation as well as on several sub-themes (e.g. transition, co-creativity, 
and interaction) within the context of Hungary and, more especially, in Budapest Metropolitan University. The statements given in the sections below refer to the comments made by the staff Delphi Panel in written form and the student focus group in oral form (later transcribed) using the terminology that was employed by the respondents.

\section{Internationalisation}

\section{Staff Delphi Panel}

The Delphi Panel described the process of internationalisation as involving information sharing, cross-cultural exchange, language learning and building valuable networks and contacts. It stimulates creativity and innovation by disrupting old patterns leading to positive change, for example in service-orientation, communication and flexible working. They agreed that creativity is an essential part of internationalisation. This confirmed one of the main research questions, which was whether creativity is one of the most important pillars of internationalisation. The greatest challenges were cited as being globalising or going beyond the local, institutional rigidity, changing ways of thinking and resolving conflicts.

\section{Student focus group}

Students seemed generally happy with their experiences of internationalisation and stated that there are many students from other countries and more than enough examples and case studies used in teaching from other countries and cultures. They also thought that there are enough opportunities through Erasmus (European Unionfunded exchange programmes), but they are not promoted well enough, for example, where students could go. They had had chances to help out at international conferences and events, experience visits from foreign students, go to talks with speakers from abroad, and to shadow industry practitioners. However again, not all of the students had known about these opportunities. They also stated that some teachers' English skills could be improved, that help with internships was not sufficient, and that the social side of their experiences could be significantly improved with some clubs, societies and excursions. In the case of students, pillars of internationalisation were not clearly identified, creativity was not specifically mentioned, but it was evident that some form of self-development or transformation took place as a result of opportunities created by internationalisation.

\section{Creativity \\ Staff Delphi Panel}

The Delphi Panel agreed that creativity in education is important but some members felt that it is not essential and not always possible. Creativity was defined by the Panel as thinking in new ways and providing (multiple) solutions for new questions and problems. Creativity helps to develop and apply new skills, attitudes and perspectives. Not all Delphi members agreed that arts-related subjects are indispensable in the context of creative education, but it was felt by many that the arts help to develop worldviews that are not attainable in any other way. However, most Delphi participants agreed that all subjects can be creative if they are taught in the right way, for example through problemsolving or finding solutions, resolving conflicts, making connections and highlighting diversity.

\section{Student focus group}

Students described how some teachers tried to develop students' creative skills more than others. They felt that the personality and technique of the teachers are important, and that interactive, informal, friendly teachers who created a good atmosphere and involved students were the most creative. They also felt that the most creative lessons took place in small groups with flexible classroom arrangements. In terms of content and delivery, they stated that lectures need more examples and case studies to be creative, that working on 'tangible' projects or in real situations are creative, for example learning to solve problems in a business. Students agreed with the Delphi Panel respondents that one does not have to talk about the arts to be creative, and cited an example of one course where arts and museums were the focus, but it was not as creative as some of the business courses. However, they had experienced creative Marketing and Human Resources courses where real-life examples and contexts were given for tasks which involved problemsolving. Overall, they agreed that the teaching tools should be varied and interesting, and that creativity is more of an approach than subject-specific content.

\section{Co-creativity}

In accordance with theories about the experience economy and the value of co-creativity, staff and students were also asked about this subtheme.

\section{Staff Delphi Panel}

The Delphi Panel agreed that co-creative education should be inspiring and engaging. Creative methodologies should be interactive, cooperative, problem-solving and group projectbased. Most Delphi members agreed that all education should be co-creative; however, they doubted whether all students were equally capable of co-creation. One or two members also pointed out that the requirement to convey facts and to cover a body of knowledge may inhibit creativity to some extent.

\section{Student focus group}

Students did not fully understand the term 'co-creativity', but understood the concepts of 'interactivity', 'involvement' and 'influence'. They agreed that there was some freedom in subject choices (but not much), and that they had some influence over course content and assessment (e.g. asking or voting for what they wanted with certain teachers). They could choose when and where to study because of the availability of online materials. Students felt that interactive teaching is very important, otherwise they feel bored, sleepy 
and uninvolved, and they enjoyed interactive or collaborative projects. Their interaction with teachers was positive, they had experienced very good interaction with other students including online forums to help students who had missed classes, share information, etc. There was also some useful interactions with companies, businesses and industries for project work, research and internships.

The second part of the main research question suggested that creativity is integral to transformational learning.

\section{Transformational learning Staff Delphi Panel}

Delphi study participants defined transformational education as a process that prepares students for working life especially in terms of skills development. They stated that students need to develop the maturity to think independently and critically, open their minds to diversity, navigating between different worldviews while retaining a sense of self. This includes developing a sense of self in both real and virtual environments. They stated that students need to be able to adapt their thinking and attitudes to cope with international workplaces and a multicultural workforce. They argued that this requires creative skills, thus partly confirming the second part of the research question. Transformational education can help develop strong community values and norms in the institution, but many participants said that staff should be trained in order to develop the right attitudes and values. In summary, the greatest challenges for transformational education according to the Delphi Panel are (1) changing the culture of the institution, (2) training staff in the necessary skills and (3) changing the attitudes of students to both learning and life.

The Delphi Panel was also asked (see Appendix 1) about their experiences of the Hungarian education system, as all of the respondents in the Delphi Panel were Hungarian. They believed that there is more freedom and flexibility at higher education level than at other levels of education, and that although Hungarian curriculum development is often preset, which limits creative curriculum development, there is room for creativity in course content, delivery, approaches and tools.

They also suggested that although Hungarian education is quite focused on facts and rote-learning, facts can be taught in a creative way. However, the panel agreed that the greatest challenges to Hungarian educational reform at higher education level are (in order of importance) the following: (1) the political, legal and regulatory system, (2) lack of institutional support or funding and (3) lack of motivation of teachers because of high workloads and low salaries.

Connected to the idea of transformational education was the idea of a 'transition university', as it had been suggested by the management that Budapest Metropolitan could be described using this term. The university may not attract those students with the highest number of points or credits on entry, but it will aim for the greatest transformation in those students, especially in skills development and vocational or career potential. The Delphi Panel understood this concept and stated that it involves student self-development from school to the workplace. This includes equipping them for the dynamic, fast-changing, competitive global environment, opening their minds to new worldviews, shaping their values and ethics (at least, in theory or ideally). The panel stated that the greatest challenges for transition universities are (1) lack of student motivation and engagement and ability to pay attention and (2) requirement of a shift from an approach where students are here just to get a degree to a transformation in attitudes to learning and knowledge acquisition.

\section{Student focus group}

The students were asked about their self-development in the context of transformational education (see Appendix 2). They stated that the international environment broadens horizons and that they became more open to different cultures and can understand them better. In terms of language development, they described how thinking in a foreign language makes you creative, because you cannot always say exactly what you want to say, so you have to paraphrase and adapt. This was especially true in small groups because everyone has to participate and speak and therefore form and give opinions. They believed that they had developed their oral, listening and written skills and had learnt how to use new tools (e.g. in technology). Many students appreciated experiencing a different education system with less 'power-distance', where students could interact with or even argue with teachers. Although the students were less direct and explicit about creativity being essential to transformational education, their discussions once again confirmed the first part of the research question that internationalisation engenders creativity.

\section{Discussion}

This article aimed to explore the relationship between internationalisation, creativity and transformation. The main research questions focused on whether creativity is an integral part of transformational learning, and whether creativity and transformation are the most important elements of internationalisation. The Delphi respondents (academic staff) clearly considered creativity to be one of the most important pillars of internationalisation. Students (focus group) did not mention creativity explicitly, but it emerged in the discussions that the process of internationalisation required a certain degree of creativity from the students (e.g. in terms of language and communication, adaptation to new and different situations). Furthermore, students also believed that internationalisation afforded them plenty of opportunities for self-development or transformation. Academic staff also confirmed this view, especially in terms of students being able to function well in international workplaces and multicultural workforces.

It should be noted that there are clear limitations to the research. The sample sizes are small although they are 
methodologically acceptable, and they represent the opinions of staff and students from only one institution. The Delphi Panel and focus group respondents were also carefully selected by the researchers, which created bias. However, it was essential that the respondents were already knowledgeable about the issues in question and that their English was good enough to respond in depth.

Further issues emerged from the research which supported some of the academic literature. Staff believed that internationalisation necessarily requires creativity, as stated by Dziedziewicz et al. (2014). Both staff and students believed that all subjects can be creative if they are taught in the right way. As stated by Bronson and Merryman (2010), creativity can take place outside the 'art room'. They quoted examples of non-arts-based courses which had been creative because of the teachers' attitudes, approaches, use of examples, or putting the theory into context (e.g. experiential learning as advocated by Pierce 1986). Although Philip (2015) has suggested that creativity is often hidden in higher education curriculum, here creativity lay rather in the delivery because the curriculum is somewhat fixed in Hungary, as stated earlier. A form of 'communicative learning' is deemed important (Dirkx 2006). Even though staff agreed that all education should be 'co-creative' and that students want to co-create, the students found it difficult to grasp the concept of 'co-creativity'. However, they understood interaction and emphasised its importance. Interaction includes their relationships with teachers, each other, support services such as administrators, and industry (e.g. internships, projects, research and conferences). In the literature, the value of co-operative and project-based learning was emphasised by Messing (2008) among others, as well as problem-solving capabilities (Stone \& Duffy 2015). There was a consensus between staff and students that facts should be learnt in a creative way, that theory should be placed in real life or that project-based context that requires problem-solving skills, international examples and case studies lead to greater understanding, and that the cultural diversity of an international group of students enhanced creativity. The students suggested that smaller group sizes facilitated this process, and staff also expressed concern that large group sizes were likely to inhibit the development of creative and transformational education for teachers.

\section{Conclusion}

The degree of transformation for the consumer can vary, according to its depth, duration and intensity. The transformation therefore exists within a spectrum, where the impact can be high or low, transient or longlasting, thought-provoking or life-altering.

(Mermiri 2009:24)

The theoretical and research dimensions in this article suggest that creativity is an integral part of transformational higher education, even if students do not recognise it explicitly. The process of internationalisation has an enormous impact on developing creative learning via cognitive and non-cognitive processes at a personal as well as an organisational level. It seems that the process of internationalisation is a challenging but positive experience for staff and students alike, and that creativity is a necessary part of transformation. Beghetto and Kaufman (2013) and Jackson et al. (2006) suggest that creativity comes at a cost, and significant investments of time and energy may be required. This will involve creativity as a transversal and transdisciplinary competence, not only one that takes place within arts-related subjects. Indeed, creativity is more of an approach than a content-specific phenomenon. Creativity requires the generation of unique ideas in the form of divergent thinking (Urban 2014) and their application to produce the best results in the form of convergent thinking (Bronson and Merryman 2010). Creativity and transformational learning are connected to disciplinary, sociocultural, global and local contextual levels, with clear connections to the work sector. Students in the focus group stated that they 'need to be able to adapt their thinking and attitudes to cope with international workplaces and a multicultural workforce'. This point was also emphasised by Stone and Duffy (2015). From the research data in this article, it is clear that the balance between higher education and the work sector is an important task requiring appropriate curriculum development and teaching methodologies, especially focusing on project methods and cooperative and problem-based learning techniques. Parallel research on best practice and discourse analysis of internationalisation in the Middle East and north Africa stressed cooperative learning, critical thinking, problemsolving, applying knowledge and discussion in the transformational process (Abouchedid \& BouZeid 2017). This study confirms their recommendations and points to a need for even more creative approaches to education and learning in higher education in the future.

\section{Acknowledgements}

Thank you to our colleagues and students for taking time out of their busy schedules to take part in the primary data collection for this research.

\section{Competing interests}

The authors declare that they have no financial or personal relationships which may have inappropriately influenced them in writing this article.

\section{Authors' contributions}

Both authors were involved in the conception and design of the research and theoretical framework.

\section{References}

Abouchedid, K. \& BouZeid, M., 2017, 'Lebanon: Legacy of the past and present challenges', in S. Kirdar (ed.), Education in the Arab World, Chapter 3, pp. 59-85, Bloomsbury, London.

Anderson, D. \& Anderson, L., 2001, Beyond change management, Jossey-Bass, San Francisco, CA.

Bauer, B. \& Szabó, A. (eds.), 2009, Ifjúság 2008: Gyorsjelentés [Youth 2008 Study], SzociálpolitikaiésMunkaügyilntézet, Budapest.

Beghetto, R.A. \& Kaufman, J.C., 2013, 'Fundamentals of creativity', Educational Leadership 70(5), 11-15. 
Bereczki, E.O., 2016, 'Mapping creativity in the Hungarian National Core Curriculum: A content analysis of the overall statements of intent, curricular areas and A content analysis of the overall statements of intent, curricular areas and education levels', The Curricul

Blessinger, P., 2015, 'The world needs more international higher education', University World News, 24 April, Issue No: 364, viewed 20 June 2017, from http://www. universityworldnews.com/article.php?story $=20150422110029960$

Brady, S.R., 2015, 'Utilizing and adapting the Delphi method for use in qualitative research', International Journal of Qualitative Methods 1-6. https://doi. org//10.1177/1609406915621381

Bronson, P. \& Merryman, A., 2010, 'The creativity crisis', Newsweek, viewed 20 April 2017, from http://www.newsweek.com/creativity-crisis-74665

Budapest Metropolitan University, 2017, About us, viewed 29 April 2017, from http:// www.metropolitan.hu/en/about-us

Cheng, Y., Wang, Q. \& Liu, C.N. (eds.), 2014, How world-class universities affect global higher education, Sense Publishers, Taipei.

Clark, C., 1991, 'The restructuring of meaning: An analysis of the impact of context on transformational learning', unpublished doctoral dissertation, Athens, GA.

Clark, M. \& Wilson, A., 1991, 'Context and rationality in Mezirow's theory of transformational learning', Adult Education Quarterly 41, 75-91. https://doi. org/10.1177/0001848191041002002

Cranton, P., 1994, Understanding and promotion transformative learning: A guide for educators of adults, Jossey-Bass, San Francisco, CA

Csikszentmihalyi, M., 1996, Creativity, Harper Collins Publishers, New York.

Csikszentmihalyi, M. \& Sawyer, K., 1995, 'Creative insight: The social dimension of a solitary moment', in R. Steinberg \& J. Davidson (eds.), The Nature of Insight, pp. 329-361, MIT Press, Cambridge, MA.

Davies, D., Jindal-Snape, D., Collier, C., Digby, R., Hay, P. \& Howe, A., 2013, 'Creative learning environments in education - A systematic literature review', Thinking Skills and Creativity 8, 80-91. https://doi.org/10.1016/j.tsc.2012.07.004

De Witt, H., Gacel-Ávila, J., Jones, E. \& Jooste, N. (eds.), 2017, The globalization of internationalisation, Routledge, London.

Dirkx, J., 2008, 'The meaning and role of emotions in adult learning', New Directions for Adult and Continuing Education 120, 7-18. https://doi.org/10.1002/ace.311

Du Preez, P., Simmonds, S. \& Verhoef, A.H., 2016, 'Rethinking and researching transformation in higher education: A meta-study of South African trends', Transformation in Higher Education 1(1), 1-7. https://doi.org/10.4102/the.v1i1.2

Dziedziewicz, D., Gajda, A. \& Karwowski, M., 2014, 'Developing children's intercultura competence and creativity', Thinking Skills and Creativity 13, 32-42. https://doi. org/10.1016/j.tsc.2014.02.006

Eliot \& Associates, 2012, The experience business: Ten top tips for great focus groups, viewed 15 March 2017, from http://www.theexperiencebusiness.co.uk/ downloads/content-docs/top ten tips.pdf

Flint, L.J., 2014, 'How creativity came to reside in the land of the gifted (and how to move it into a new neighborhood)', Knowledge Quest 42(5), 65-69.

Gordon, T.J., 1994, The Delphi method. Futures research methodology, viewed 20 March 2017, from http://www.gerenciamento.ufba.br/Downloads/delphi\% 20(1).pdf

Habibi, A., Sarafrazi, A. \& Izadyar, S., 2014, 'Delphi technique theoretical framework in qualitative research', The International Journal of Engineering and science 3(4), 8-13.

Holland-Wade, G., 1998, 'A concept analysis of personal transformation', Journal of Advanced Nursing 28(4), 713-719. https://doi.org/10.1046/j.1365-2648.1998. Advanced
00729.x

Hsu, C. \& Sandford, B.A., 2007, 'The Delphi technique: Making sense of consensus. Practical assessment', Research \& Evaluation 12(10), 1-8.

Jackson, N., Oliver, M., Shaw, M. \& Wisdom, J., 2006, Creativity in higher education. An imaginative curriculum, Routledge, New York.

Jones, A., 2009, 'Generic attributes as espoused theory: The importance of context', Higher Education 58(2), 175-191. https://doi.org/10.1007/s10734-008-9189-2

King, K., 1996, 'Identifying factors that promote perspective in higher education: A model', paper presented at the Eastern Adult, Continuing and Distance Education Research Conference, University Park, PA, 24-26 October.

Krueger, R.A., 2002, Designing and conducting focus group interviews, viewed 28 March 2017, from http://www.eiu.edu/ihec/Krueger-FocusGroupInterviews.pdf

MacDonald, S. \& Headlam, N., 2011, Research methods handbook, CLES, Manchester.

Maringe, F. \& Foskett, N. (eds.), 2010, Globalization and internationalisation in higher education, Continuum International Publishing Group, London.

Mermiri, T., 2009, Beyond experience: Culture, consumer \& brand, the transformation economy, Arts \& Business, London.
Merriam, S., 2004, 'The role of cognitive development in Mezirow's transformational learning theory', Adult Education Quarterly 55(1), 60-68. https://doi.org/ $10.1177 / 0741713604268891$

Messing, V., 2008, 'Good practices addressing school integration of Roma/Gypsy children in Hungary', Intercultural Education 19(5), 461-473. https://doi. org/10.1080/14675980802531721

Mezirow, J., 1978, Education for perspective transformation: Women's re-entry programs in community colleges, Teacher's College, Columbia University, New York.

Mezirow, J., 1991, Transformative dimensions of adult learning, Jossey-Bass, San Francisco, CA

Mezirow, J., 1994, 'Understanding transformation theory', Adult Education Quarterly 44(4), 222-232. https://doi.org/10.1177/074171369404400403

Mezirow, J., 2000, 'Learning to think like an adult: Core concepts in transformation theory', in J. Mezirow (ed.), Learning in transformation: Critical perspectives on a theory in progress, Jossey-Bass, San Francisco, CA.

Morell, A. \& O'Connor, M., 2002, 'The transtheoretical model of the stages of change and the phases of transformative learning: Comparing two theories of transformational change', Journal of Transformative Education 3(49), 392-415.

Mullet, D.R., Willerson, A.N., Lamb, K.N. \& Kettler, T., 2016, 'Examining teacher perceptions of creativity: A systematic review of the literature', Thinking Skills \& Creativity 21, 9-30. https://doi.org/10.1016/j.tsc.2016.05.001

Munday, I., 2016, 'A creative education for the day after tomorrow', Journa of Philosophy of Education 50(1), 49-61. https://doi.org/10.1111/14679752.12172

Okoli, C. \& Pawlowski, S.D., 2004, 'The Delphi method as a research tool: An example, design considerations and applications', Information \& Management 42, 15-29. https://doi.org/10.1016/j.im.2003.11.002

Philip, R., 2015, 'The invisibility cloak of creativity', Higher Education Research \& Development 34(2), 436-438. https://doi.org/10.1080/07294360.2014.980880

Pierce, G., 1986, 'Management education for an emergent paradigm', unpublished doctoral dissertation, Teacher's College, Columbia University, New York.

Pine, J.B., 2015, 'How B2B companies create economic value by designing experiences and transformations for their customers', Strategy \& Leadership 43(3), 2-6. https://doi.org/10.1108/SL-03-2015-0018

Pine, J.B. \& Gilmore, J.H., 2014, 'A leader's guide to innovation in the experience economy', Strategy \& Leadership 42(1), 24-29. https://doi.org/10.1108/SL-092013-0073

Quinn, R., 1996, Deep change, Jossey-Bass, San Francisco, CA.

Radclyffe-Thomas, N., 2015, 'Fashioning cross-cultural creativity: Investigating the situated pedagogy of creativity', Psychology of Aesthetics, Creativity, and the Arts 9(2), 152-160. https://doi.org/10.1037/aca0000014

Sohn, B.K., Plaas, K., Franklin, K., Dellard, T., Murphy, B., Greenberg, K.H. et al., 2016 'Freedom to connect: Insight into the existential dimension of transformative learning in a graduate seminar', Journal of Transformative Education 14(3), 178-199.

Sternberg, R.J. (ed.), 1999, Handbook of creativity, Cambridge University Press, Cambridge.

Stone, G.A. \& Duffy, L.N., 2015, 'Transformative learning theory: A systematic review of travel and tourism scholarship', Journal of Teaching in Travel and Tourism 15(3), 204-224.

Szabó, A., Bauer, B. \& Laki, L. (eds.), 2001, Ifjúság 2000. Tanulmányok I, Nemzetilfjúságkutatólntézet, Budapest, pp. 61-115.

Szikra, D., 2014, 'Democracy and welfare in hard times: The social policy of the Orbán Government in Hungary between 2010 and 2014', Journal of European Socia Policy 24(5), 486-500.

Tolliver, D. \& Tisdell, E., 2006, 'Engaging spirituality in the transformative higher education classroom', in E. Taylor (ed.), New directions for adult and continuing education. Teaching for change: Fostering transformative learning in the classroom, vol. 19, Jossey-Bass, San Francisco, CA.

Urban, K.K., 2014, 'From creativity to responsible Createlligence', Gifted Education International 30(3), 237-247.

Watts, L.S. \& Blessinger, P. (eds.), 2017, Creative learning in higher education, Routledge, London.

Zsolnai, A. \& Lesznyák, M., 2015, 'Pluralism and values in education in Hungary Changes between 1990 and 2012', Journal of Beliefs \& Values 36(2), 142-155. https://doi.org/10.1080/13617672.2015.1053721 


\section{Appendix 1 Delphi Panel Questions}

1. Mezirow (1978) stated that development of a new worldview is at the heart of transformational learning. Do you agree that the main focus of transformational education should be on the self-development of students including their (world)views and attitudes? (Please give reasons for your answer.)

2. It has been said that creativity is a key constituent of the transformation economy (Mermiri 2009). Do you agree that creativity is an essential part of transformational education? Please explain why or why not.

3. Is it possible to develop creative education without including arts-related subjects? (Please explain your answer.)

4. Do you agree that education should be 'co-creative' (i.e. students help to create and shape their own learning experiences)? In what ways can this be facilitated?

5. Internationalisation seems to be an important part of the transformation of education today. In what ways could internationalisation positively transform an institution, its staff and students?

6. To what extent do you think that creativity is essential to the process of internationalisation? In what ways might creativity be used?

7. Hungarian curriculum development is often preset which limits creative curriculum development. Is it still possible to be creative in curriculum development, course development and delivery? If so, how?

8. The Hungarian education system has sometimes been criticised for focusing too much on testing and 'rote learning' (learning facts by heart and repeating them). This can create more 'instrumental' approaches to education based mainly on gaining a degree and a career (Szabó, Bauer \& Laki 2001) rather than more creative aspects of learning and personal selfdevelopment. Can you see any possibilities to change this and if so, how?

9. Please add any further comments about transformational education and creativity here if it has not been covered in your answers so far.

\section{Appendix 2}

\section{Student focus group (handout given to students) \\ Internationalisation, Creativity and Transformational Education Student focus group}

\section{Aims and Definitions}

The aim of this focus group is to discuss the themes of 'creativity', 'internationalisation', and 'transformational education'.

- Creativity has many definitions and can relate specifically to the arts and related courses, or can mean new and innovative approaches to teaching, learning, research, etc. in subjects that are not related to the arts.

- Internationalisation means the move towards attracting more international students, introducing more international materials into the curriculum and courses, and offering international experiences to students (e.g. exchanges, internships).

- Transformational education can refer to transformation of the national education system (e.g. in Hungary), transformation within an institution (e.g. an internationalisation process), transformation of teaching and learning methods (e.g. curriculum development, approaches to course delivery, new teaching tools) and transformation of staff and students (e.g. training, self-development).

\section{Questions for Discussion}

1. Would you say that your education at Metropolitan University so far has been in some way 'transformational' - e.g. did it change your attitude, way of thinking, gave you new perspectives on life? Overall, has there been some selfdevelopment?

2. Would you say that your education at Metropolitan University has been 'creative' in some way? For example, in terms of content or subjects studied, approaches to teaching, creative project work? Which of the subjects that you studied did you find the most creative and why?

3. Do you think that your education has been 'co-creative' in some ways - e.g. did you feel that you could make some decisions about what to study and how to study or did the teachers decide everything? Which of the subjects that you studied did you find the most co-creative and why?

4. Do you think that your education has been interactive enough? Did you have opportunities to contribute ideas, make suggestions and do independent or group tasks?

5. Budapest Metropolitan University is 'internationalising'. Do you feel that your experience of the education has been international enough in its content, approach, case studies, internship opportunities, etc.? Can you give any good examples? Which of the subjects that you studied did you find the most international and why?

6. Outside the classroom, have you had many opportunities to get involved in international or creative activities or events at Metropolitan? Can you give any positive examples?

7. Do you think that creativity needs to include arts-related subjects or activities or is it possible to be creative without focusing on the arts? For example, can economics or statistics be creative?

8. If you could make any recommendations for Metropolitan as a University, what would you improve in terms of:
(a) Creativity
(b) Internationalisation
(c) Personal transformation or development opportunities 